\title{
Effect of FK506 administration in alpha motor neurons after primary and delayed repair of the sciatic nerve
}

\author{
Umut Özsoy ${ }^{1}$, Fatoş Belgin Yıldırım ${ }^{1}$, Bahadır Murat Demirel ${ }^{2}$, Arzu Hızay ${ }^{1}$, Levent Sarıkcıŏlu ${ }^{1}$, \\ Necdet Demir ${ }^{3}$, Gamze Tannöver ${ }^{3}$, Bikem Süzen $^{1}$, Nurettin Oğuz ${ }^{1}$ \\ ${ }^{1}$ Department of Anatomy, Faculty of Medicine, Akdeniz University, Antalya, Turkey \\ ${ }^{2}$ Department of Anatomy, Faculty of Medicine, SANKO University, Gaziantep, Turkey \\ ${ }^{3}$ Department of Histology and Embryology, Faculty of Medicine, Akdeniz University, Antalya, Turkey
}

\begin{abstract}
Objectives: FK506 is an effective immunosuppressive drug for treating graft rejection in transplants patients. However, the neuroregenerative effect of FK506 has been well described in the literature. The aim of this study was to investigate the effects of FK506 in alpha motor neurons after primary and delayed repair of sciatic nerve.
\end{abstract}

Methods: Rats ( $n=72$ ) were divided into 6 groups. Control, sham-operated, primary repair FK506 (-), primary repair FK506 (+), delayed repair FK506 (-), and delayed repair FK506 (+) groups.

Results: After injury, the normal structure of the motor neuron perikarya was maintained by primary repair in the FK506 (+) group. In the delayed repair group, beneficial effect of FK506 was found to be less effective. The SFI value reached -50 recovery level in the FK506-treated group earlier than those of not FK506-treated groups.

Conclusion: Beneficial effect of FK506 has been approved by functional and ultrastructural data in both of primary and delayed repair groups.

Keywords: delayed repair; FK506; primary repair; regeneration; sciatic nerve

Anatomy 2016;10(1):30-39 @2016 Turkish Society of Anatomy and Clinical Anatomy (TSACA)

\section{Introduction}

Axotomy of the peripheral nerves causes retrograde cell death in the dorsal root ganglion neurons. Following peripheral nerve injury, the axotomized motor and sensory neurons undergo a series of retrograde degenerative changes which may result even in neuronal death. ${ }^{[1-4]}$ The degenerative changes are caused by injury-induced interruption of the flow of neurotrophic factors from periphery to neuronal body by retrograde transport. ${ }^{[5-9]}$ Degenerative changes occurring following peripheral nerve injuries vary with the subject's age, neuron type, lesion level, postoperative survival time, and type of injury. For example, in motor and sensory neurons of newborn animals, cell death has been reported in almost all types of peripheral nerve injury. ${ }^{[4,10]}$ However, after peripheral nerve transection, degeneration has been reported ${ }^{[11-14]}$ in dorsal root ganglia ${ }^{[15]}$ as well as motor neurons of cranial nerves and spinal cord. ${ }^{[16-19]}$ Some authors ${ }^{[19-23]}$ reported no loss of motor neurons in peripheral nerve crush injury, some studies also reported motor neuron survival following permanent peripheral nerve cut or limb amputation. ${ }^{[2,24,25]}$

FK506 (also known as Tacrolimus, Prograf) is a powerful immunosuppressive drug for treating graft rejection and is reputed to have a superior potency relative to Cyclosporine A (CsA) in transplant patients for prevention of graft rejection. ${ }^{[2]}$ FK506 is known to inhibit calcineurin-mediated T-cell activation by forming a complex with FK506 binding protein (FKBP-12). ${ }^{[27,28]}$ However, FK506 also has a well-studied neuroregenerative effect 
that may be related to FKBP-12 operating through a separate mechanism. ${ }^{[2]}$

Effect of FK506 on different models has been well documented in the literature. FK506 has been shown to exert neuroprotective effects in degenerative diseases, ${ }^{[0]}$ ischemic insults, ${ }^{[1-33]}$ spinal cord injury, ${ }^{[34,35]}$ and neurite outgrowth in vitro. ${ }^{[6,37]}$ Furthermore, treatment with FK506 has also been reported to enhance the rate of axonal regeneration in crush injury model ${ }^{[38-41]}$ and in a peripheral nerve grafted into the injured spinal cord. ${ }^{[42]}$ FK506 has been shown in many studies to enhance recovery after immediate $^{[43]}$ or delayed ${ }^{[2,38,44]}$ nerve repair. FK506 promotes neurite outgrowth in vitro and its efficiency in enhancing nerve regeneration and accelerating functional recovery has been demonstrated in transection, ${ }^{[4-48]}$ crush, ${ }^{[39,40,43,49]}$ isograft, ${ }^{[50-52]}$ and allograft models. ${ }^{[53-55]}$

In clinical practice, diagnosis and treatment of patients with peripheral nerve injuries is often delayed. The effect of a delayed nerve repair on nerve regeneration and muscle reinnervation is still not well understood. This is surprising, because in the clinical routine an immediate reconstruction of the lesioned nerve is seldom possible. In contrast to typical animal models for nerve regeneration studies, there is a certain denervation time of the affected nerve between lesion and reconstruction. The results of the few animal studies using different nerves, animal models, and methods are contradictory. ${ }^{[56-61]}$ Some of them showed that an immediate nerve suture was superior to any delayed nerve suture, whereas others reported no differences. Therefore, studying on a more relevant model of nerve reconstruction is important.

Although immediate subcutaneous applications of FK506 after incision have been reported as the most effective method, ${ }^{[29]}$ delayed or intermittent applications have also been reported as effective methods. ${ }^{[62]}$ In a recent report, it has been demonstrated that the delayed administration of FK506 after surgery (even a 7-day-delay) causes reduction in axonal regeneration. ${ }^{[2]}$ In literature, beneficial effects of the FK506 have been reported in peripheral nervous system. However, effect of FK506 on alpha motor neurons has not been reported. Therefore, in the present study we aimed to study effects of FK506 on alpha motor neurons after primary and delayed repair of sciatic nerve.

\section{Materials and Methods}

\section{Animals}

A total of 72 female Wistar rats (200 to $250 \mathrm{~g}$ ) were used in the present study (Table 1). We used female rats, since it has been reported that testosterone accelerates the regeneration of peripheral nerves. ${ }^{[6,64]}$ The rats were divided into 6 groups as follows: Group 1, control; Group 2, shamoperated; Group 3, primary repair FK506 (-); Group 4, primary repair FK506 (+); Group 5, delayed repair FK506 $(-)$, and Group 6, delayed repair FK506 (+). Six animals were housed per cage and maintained on a 12:12 h lightdark cycle; lights on from 7.00 to 19.00 . Food and water were provided ad libitum. All procedures were reviewed and approved by the Animal Care and Usage Committee of Akdeniz University (protocol number 04-17).

Two subjects from the FK506 (+) and FK506 (-) groups each were excluded from the study due to postoperative death within a week. New subjects were operated in place of these, and the necessary postoperative care and FK506 applications were performed.

\section{Sciatic nerve injury}

Before surgery, animals were anesthetized with intramuscular injection of a mixture of Xylazine $\mathrm{HCl}(15 \mathrm{mg} / \mathrm{kg})$ and Ketamine $(100 \mathrm{mg} / \mathrm{kg})$. The left side of the hindlimb was shaved and swabbed with antiseptic solution. A longitudinal cutaneous incision was made in the back of the thigh. Dissection was carried out along a plane separating the hamstring and gluteal muscles to expose the sciatic nerve. Careful dissection was performed to isolate the sciatic nerve from the surrounding connective tissue over a length of 2 to $2.5 \mathrm{~cm}$. The sciatic nerve was unilaterally injured by microscissors (Figure 1a-c).

Table 1

Classification and number of study groups.

\begin{tabular}{llcccc}
\hline & $\mathbf{n}$ & Cut injury & Primary repair & Delayed repair & FK506 treatment \\
\hline Group 1: control & 12 & & & & \\
Group 2: sham-operated & 12 & & & & - \\
Group 3: primary repair & 12 & + & + & & + \\
Group 4: primary repair + FK506 & 12 & + & + & + & - \\
Group 5: delayed repair & 12 & + & & + & + \\
Group 6: delayed repair + FK506 & 12 & + & & + \\
\hline
\end{tabular}


In the primary repair group, the cut nerve stumps were coapted (totally 4 sutures) with 10.0 suture material (Figure 1d). The wound was closed with 2-0 suture material and rats were allowed to recover. In the shamoperated group, after a longitudinal cutaneous incision, the sciatic nerve was exposed and the wound was closed without sciatic nerve injury. In the delayed repair group, the skin was closed following the nerve cut. At the end of a seven-day delay period, the sprouted axons in the proximal nerve stump were pruned to refresh the cut. After this procedure, the cut nerve stumps were coaptated the same way as in the primary repair group.

\section{FK506 administration}

$5 \mathrm{mg} / \mathrm{kg}$ /day subcutaneous FK506 (Prograf, Eczacibaşı, Istanbul, Turkey) administration was performed from the day of sciatic nerve injury until the day of sacrification. The FK506 administration was not interrupted during
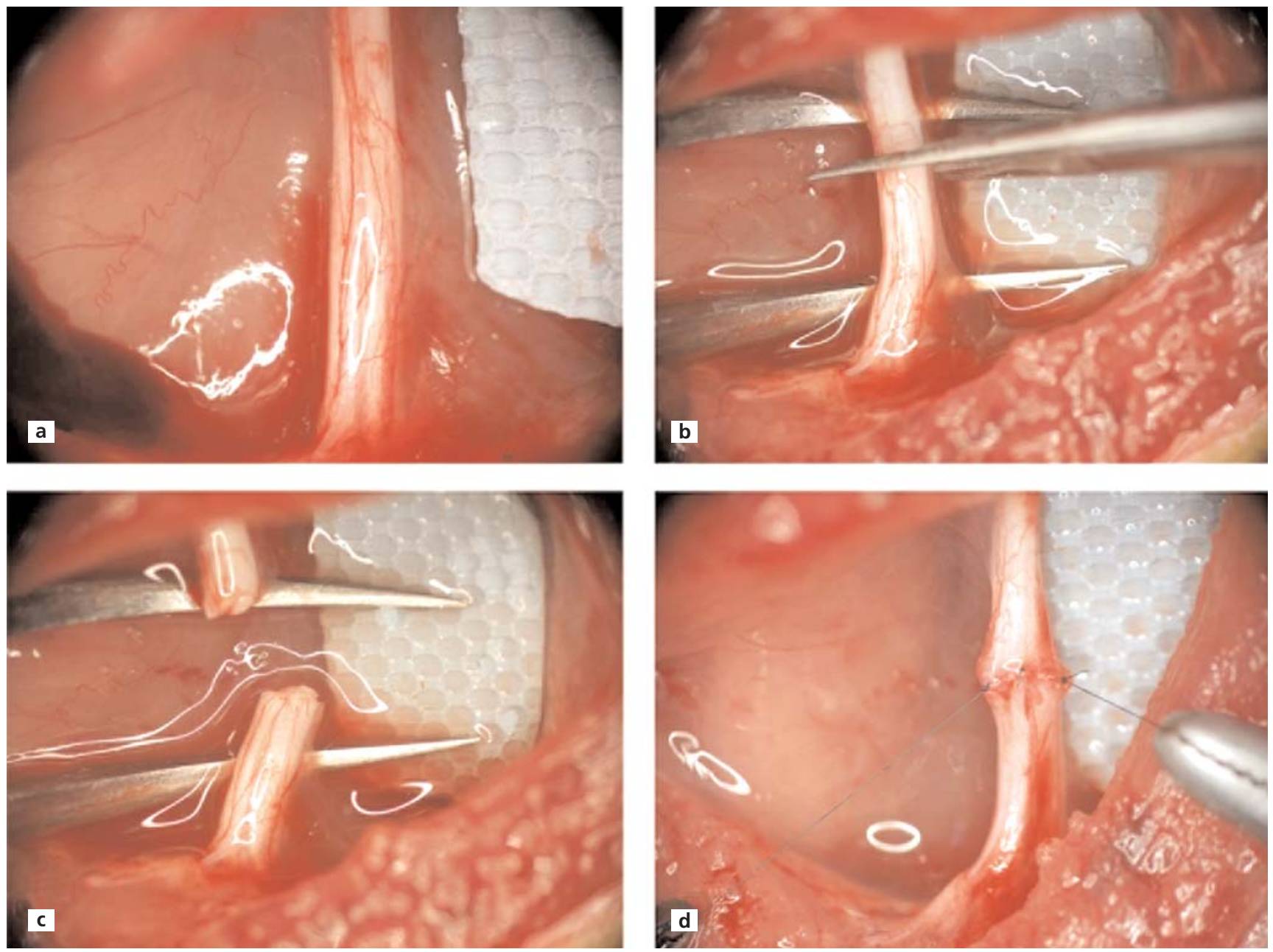

Figure 1. Nerve injury. (a) Normal appearance of the sciatic nerve, (b, c): nerve cut, (d) epineural nerve coaptation. [Color figure can be viewed in the online issue, which is available at www.anatomy.org.tr] 
tocopy paper. From the footprints, the sciatic function index (SFI) was calculated using the formula developed by Bain et al. ${ }^{[67]}$ An SFI of 0 was considered normal, whereas an SFI of -100 meant total impairment. An experienced observer analyzed the walking patterns on the 1st, 2nd, $3 \mathrm{rd}, 4$ th, 5th, and 6 th postoperative weeks.

\section{Sensory function}

Functional sensory recovery was analyzed by pinch test. The sole of the foot was pinched using a forceps. A gradual scale with four levels was used to assess withdrawal reflex (sensory recovery as: no response (Grade 0), mild response (Grade 1), moderate response (Grade 2), and full response (Grade 3). Animals showing full withdrawal response to pinch (Grade 3) were noted for further statistical analysis. Withdrawal response of animals was noted on the 1 st, $2 \mathrm{nd}, 3 \mathrm{rd}, 4 \mathrm{th}, 5$ th, and 6 th postoperative weeks.

\section{Tissue collection}

On the last postoperative day, rats were anesthetized with a combination of Ketamine (Ketalar $\left.{ }^{\circledR}\right)(100 \mathrm{mg} / \mathrm{kg}, \mathrm{IM})$ and Xylazine $\mathrm{HCl}$ (Rompun $\left.{ }^{\circledR}\right)(15 \mathrm{mg} / \mathrm{kg}, \mathrm{IM})$ diluted in saline. Rats were perfused transcardially with $250 \mathrm{ml}$ heparinized saline and spinal cord was dissected free. Spinal cord samples (approximately $1 \mathrm{~cm}$ ) were harvested from the level of lumbar intumescence. Care was taken not to damage spinal cord tissue while dissecting the surrounding bony structures. Sciatic motor neuron pool was sampled after transverse sectioning of the lumbar intumescence. Sciatic nerve samples were harvested $0.5 \mathrm{~cm}$ below the lesion site and immediately transferred to routine electron microscopic tissue preparation procedure.

\section{Electron microscopic analysis}

Spinal cord samples (each $1 \mathrm{~mm}^{3}$ ) belonging to lumbar intumescence were fixed with $2 \%$ glutaraldehyde in $0.1 \mathrm{M}$ Sorensen's phosphate buffer $(\mathrm{pH} 7.2)$ at $+4^{\circ}$ for two hours. The tissue samples were post-fixed in 1\% osmium tetroxide $\left(\mathrm{OsO}_{4}\right)$ solution for one hour. Samples were dehydrated through a gradually increasing series of ethanol and embedded in Araldite resin (Araldite CY 212, $91 \mathrm{ml}+$ dodecenyl succinic anhydride (DDSA) $84 \mathrm{ml}+\mathrm{N}, \mathrm{N}-$ dimethylbenzylamine (BDMA) $3.5 \mathrm{ml}$, TAAB Company, Aldermaston, UK). Semi-thin (1 micrometer) and ultrathin (40-60 nm) sections were obtained using diamond knives on a Leica ultramicrotome (Leica Ultracut, UCT, Leica MZ6; Leica Microsystems GmbH, Wetzlar, Germany). Sections were examined to determine the ventral horn for motor neuron pool. Then, ultra-thin sections were obtained from area of interest. Ultra-thin sections were collected on copper grids (Mesh 100, TAAB, England) coated with Formvar 15/95 Resin (EMSElectron Microscopy Sciences, Fort Washington, PA,
USA). In semi-thin sections (1 micrometer), routine toluidine blue staining method was applied for orientation. In ultra-thin sections, double-contrast staining was applied with uranyl acetate $(100 \mathrm{ml}$ methanol and $5 \mathrm{~g}$ uranyl acetate) and Reynold's lead nitrate solution. Ultra-thin sections were examined using a transmission electron microscope (Leo 906E; Zeiss, Jena, Germany).

\section{Data analysis}

All data (mean \pm standard deviation) were analyzed with SPSS Statistical Package for Social Sciences (SPSS) software (version 11.0; SPSS Inc, Chicago, IL, USA). A p value less than 0.05 was considered as statistically significant. Comparison of SFI data was done using one way ANOVA (with Tukey's post hoc test) and Pinch test data was done by chi-square test.

\section{Results \\ SFI values}

The print length (PL) of the animals in all experimental groups was considerably longer, and toe spreading and intermediate toe spreading was narrower on the injured site on the day following injury. The SFI values were $90.65 \pm 5.29,-99.65 \pm 6.42$ for Group 3 (primary repair) and Group 5 (delayed repair), respectively. The SFI value in Group 3 (primary repair) and Group 5 (delayed repair) could not recover to the -50 values even at the end of the 6th postoperative weeks (Figure 2). FK506 treatment

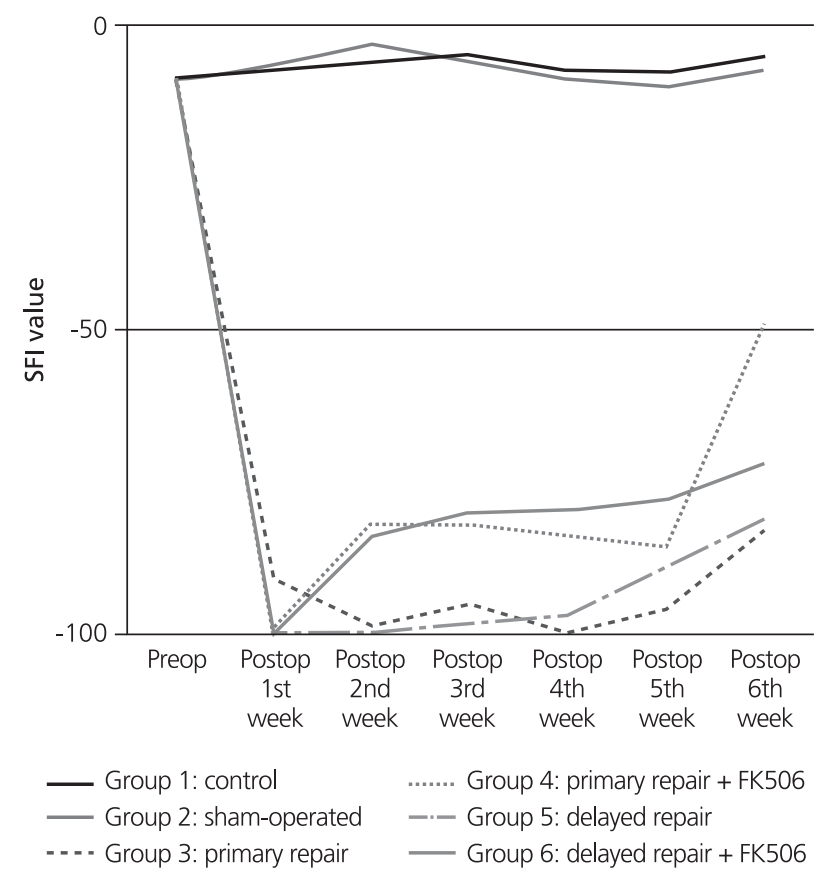

Figure 2. Sciatic function index values of groups. 
affected the onset week of the -50 level of SFI among the FK506 treated groups, i.e. while Group 4 (primary repair + FK506) reached -50 levels Group 6 (delayed repair + FK506) could not reach at the 6th postoperative week. At the end of the 6th postoperative week no significant difference was observed between Group 2 (sham-operated) and Group 4 (primary repair + FK506).

\section{Onset day of withdrawal response to pinch}

The onset day of withdrawal to pinch appeared at the 3rd postoperative week in Group 4 (primary repair + FK506) and Group 5 (delayed repair). In this week, only two animals displayed Grade 3 withdrawal to pinch. However, seven, two, and three animals showed withdrawal to pinch in Group 4 (primary repair + FK506), Group 5 (delayed repair), and Group 6 (delayed repair + FK506), respectively (Figure 3). At the end of the 6th postoperative week no significant difference was observed between Group 2 (sham-operated) and Group 4 (primary repair + FK506).

\section{Electron microscopic evaluations}

The ultrastructure of sciatic nerve samples of the control and sham-operated groups displayed normal structural organization (Figure 4). Ventral horn samples in the control group were compared to those of primary repair and delayed repair groups with or without FK506 treatment. The ultrastructural morphology of the ventral horn in the primary repair group with FK506 seemed to be similar to the control groups. There was no apparent structural damage on the pericaryon of motor neurons. Also, no defect or edema was observed in the neuropil area and neurons. However, clear oedematous gaps wrapping the pericaryons were evident in Group 3 (primary repair). In this group, capillary diameters were observed to be narrowed. Moreover, oedematous areas were observed in the astrocytic feet.

The preservative effect of FK506 was revealed in the delayed repair group as well as the primary repair group ultrastructurally. Also, no neuropil oedemas or deformation areas were evident in Groups 4 and 6. On the other

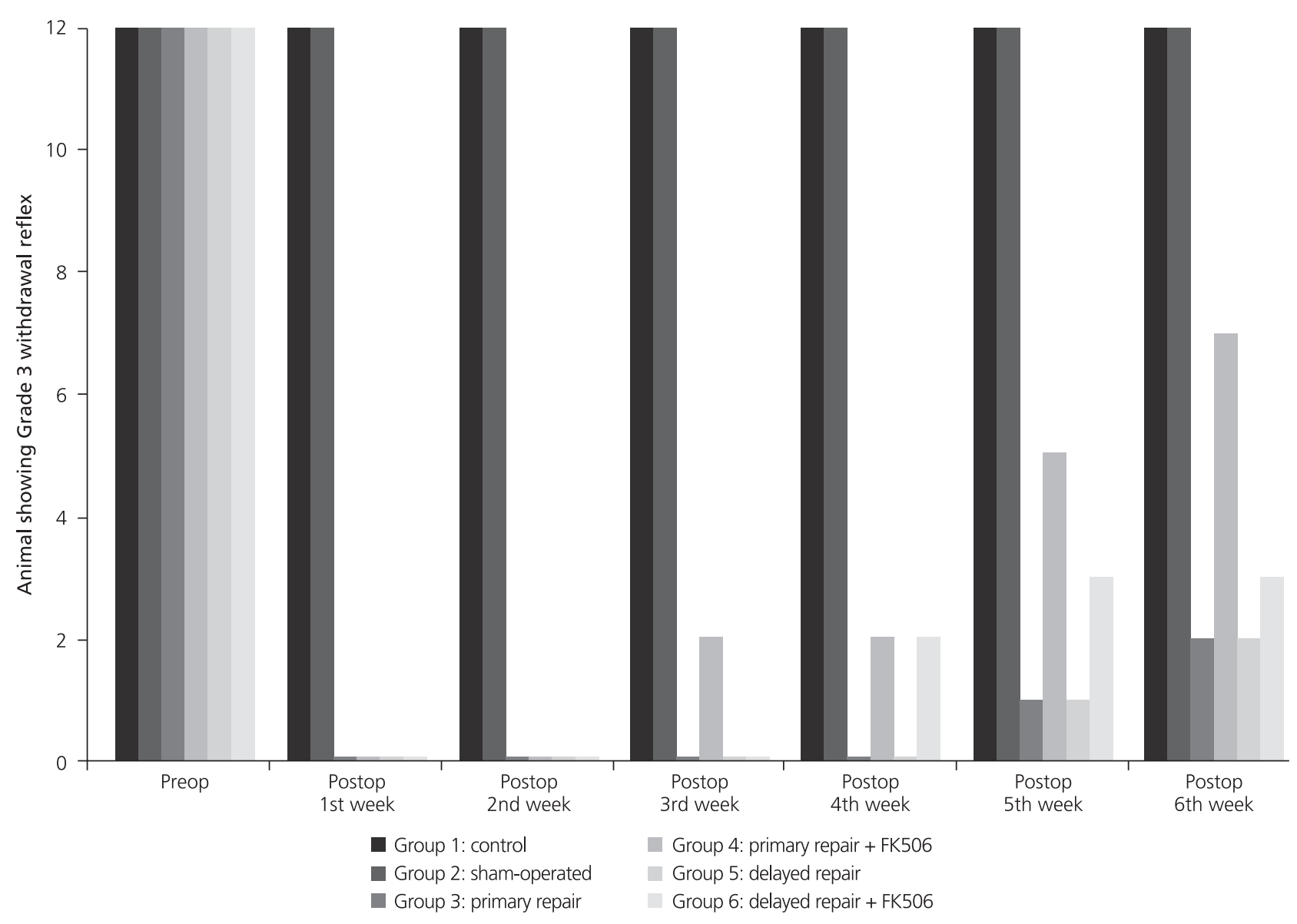

Figure 3. Number of animals showing Grade 3 withdrawal response. 

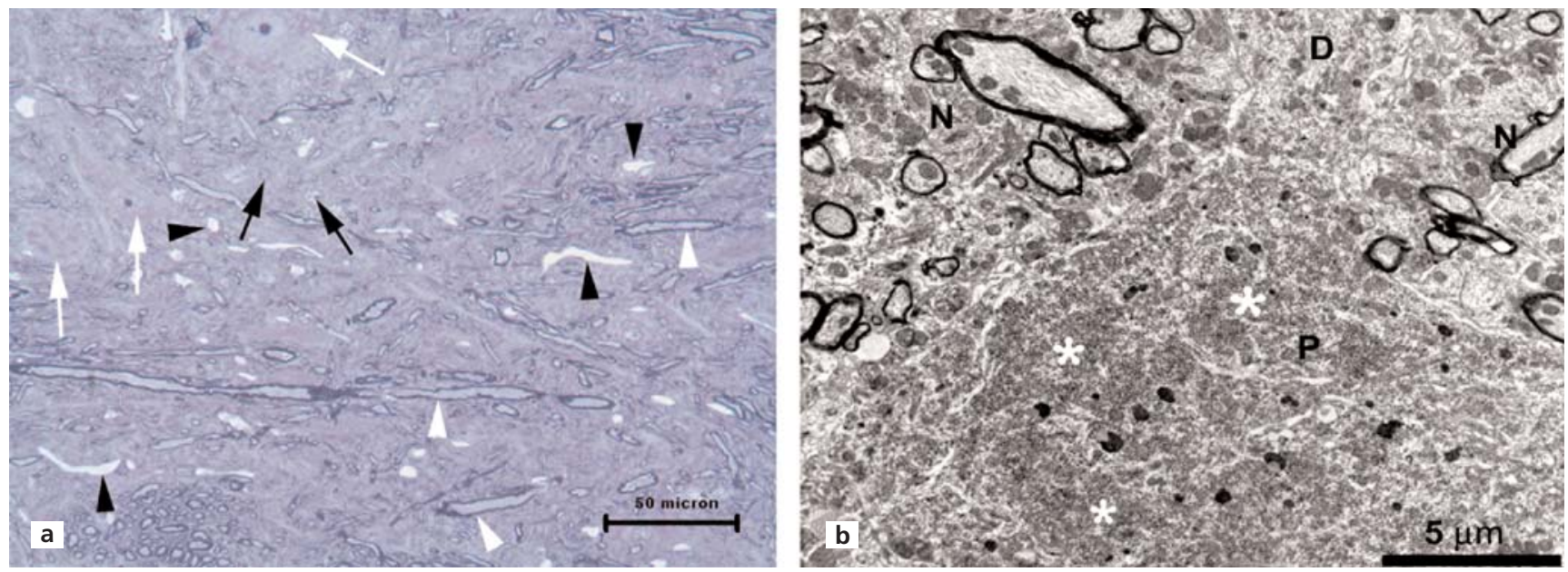

Figure 4. The light and transmission electron micrographs of motor neurons in the control group. (a) Motor neurons (white arrows), glia (black arrows), capillaries (black arrowheads), myelinated axons (white arrowheads) and different sizes of the capillaries are shown in semithin sections. (b) The ultrastructural feature of neuropils $(\mathrm{N})$ were observed with neurons with Nissl bodies $\left.{ }^{*}\right)$ in cytoplasm and dendrites. [Color figure can be viewed in the online issue, which is available at www.anatomy.org.tr]

hand, FK506 was not properly effective on the ultrastructure of neurons (Figure 5).

\section{Discussion}

A correlation between time of nerve repair and functional recovery was reported in a number of studies. ${ }^{[68-71]}$ Timedependent changes that affect the clinical outcome have also been reported following nerve injury. ${ }^{[7,48,58,69-73]}$ Therefore, relationship between the time of injury, surgical repair and initiation of drug therapy are important factors in usage of agents with neurodegenerative and/or neuroprotective effects. In the present study, we limited postoperative period as 6 weeks to observe the effects of FK506 on functional, ultrastructural properties of nerve recovery. This postoperative time period was also used in other studies. $^{[43,74-77]}$

Sulaiman et al. ${ }^{[48]}$ investigated the effect of FK506 treatment in chronic denervation and chronic axotomy models which were formed by a total transection of the tibial and common peroneal nerves. In the chronic axotomy model, at the end of a 2-month delay, the proximal stump of the tibial nerve was coaptated to the freshly cut distal stump of the peroneal nerve. In another model of chronic denervation, after a 2-month of delay, the proximal stump of the peroneal nerve was coaptated to the freshly cut distal stump of the tibial nerve. Afterwards, they reported an increase in the number of HRP-labeled motor neurons, number of axons and myelin sheath thickness after daily administration of $5 \mathrm{mg} / \mathrm{kg}$ FK506 in chronic axotomy model. Although the study of Sulaiman et al. $^{[48]}$ was not applicable in clinical practice, their results are important in terms of giving an idea about the effects of FK506.

In clinical practice, diagnosis and treatment of patients with peripheral nerve injuries is often delayed. Coaptation of the transected nerve stumps cannot be performed immediately after incision. However, in the experimental setups, neuroregenerative/neuroprotective agents are often applied soon after nerve cut injury and coaptation. In the present study, we applied delayed nerve repair model in line with the frequently encountered clinical scenario, and investigated the ultrastructural effects of FK506 on the alpha motor neurons. We found that FK506 treatment resulted in normal motor neuron structure. This finding was not observed in FK506 (-) group. Additionally, in the delayed repair group, in which nerve repair was applied 7 days after the injury, beneficial effect of FK506 was lower than those of the primary repair group. In a recent study, Brenner et al. ${ }^{[29]}$ investigated the neuroregenerative effect of FK506. In their study, they applied FK506 after primary and delayed repair and found that FK506 administration after delayed repair did not cause an increase in the nerve regeneration. Additionally, they showed a decrease in the number of retrogradely labeled motor neurons.

Ma et al ${ }^{[78]}$ found $21-31 \%$ loss of motor neurons at 8 and 16 weeks following $\mathrm{C} 7$ spinal nerve injury. Effects of the delayed repair after nerve cut injury were not only investigated on the spinal nerves, but also on the cranial nerves. Guntinas-Lichius et al. ${ }^{[7]]}$ examined the effects of delayed repair using the hypoglossal-facial anastomosis model to reanimate the facial nerve. In addition, they reported that this model was more realistic for repair of 

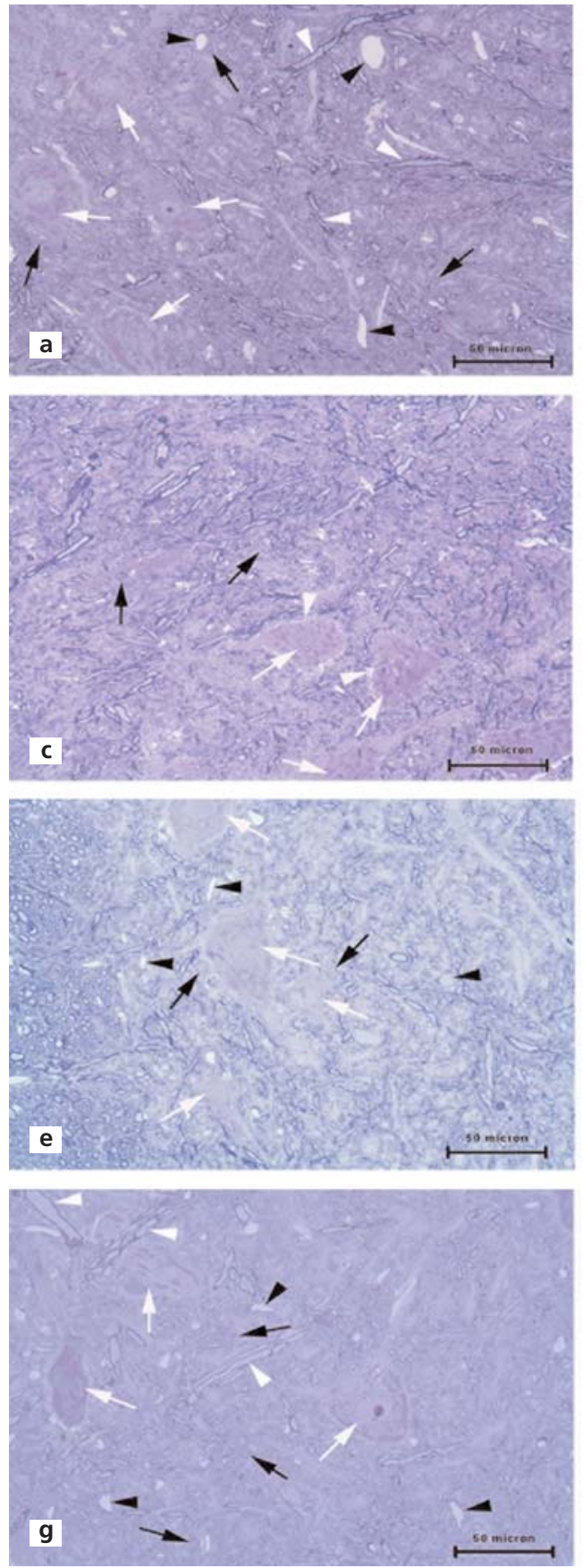
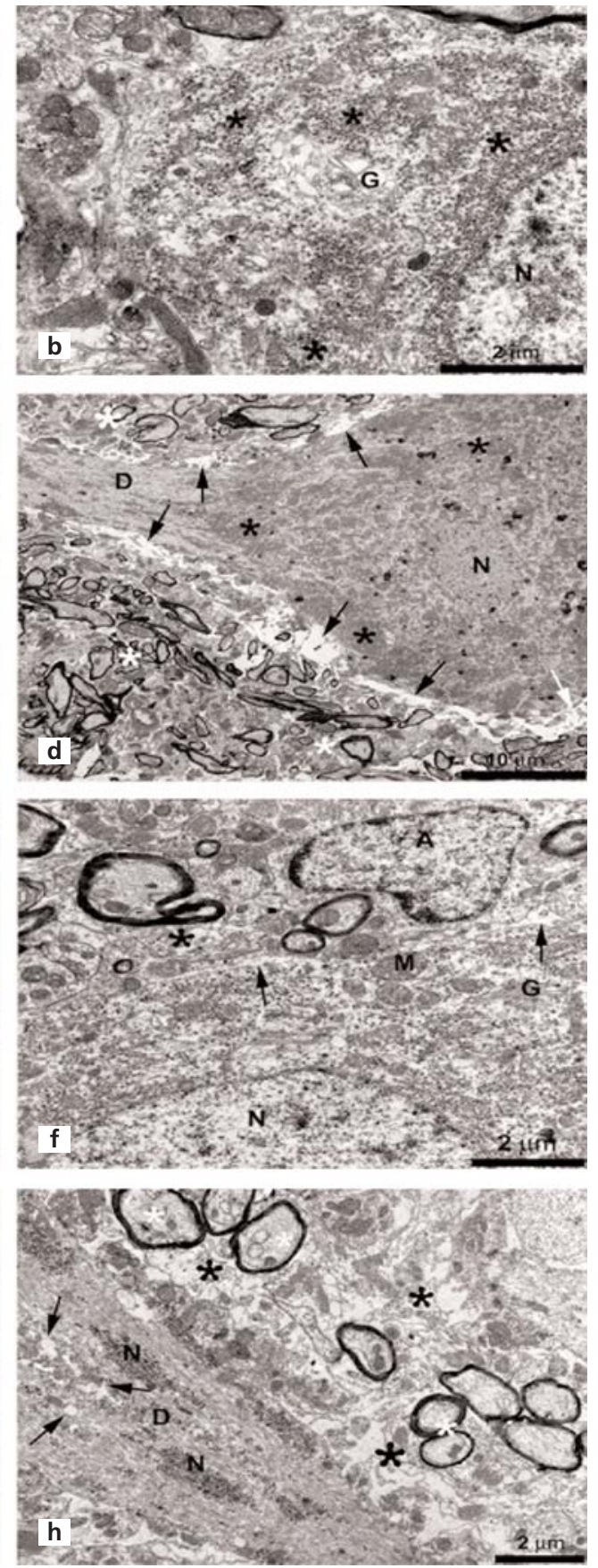

Figure 5. Representative pictures of motor neurons in the experimental groups obtained by light and electron microscopy. (a) Motor neurons (white arrows), glia (black arrows), myelinated axons (white arrowheads) and capillaries can be seen in semithin sections in primary repair with FK506 groups. (b) Motor neurons with Nissl bodies (*), enlarged Golgi cisterns (G) and euchromatic nuclei (N) in ultrathin sections in the same area. (c) The semithin sections showing motor neurons (white arrows) consisting of enlarged edematous areas (white arrowheads) and glia nuclei in neuropils of the primary repair without FK506 group. (d) Transmission electron micrographs of surrounded motor neurons show dense edematous areas and also separation areas (black arrows) in the same group. In addition, cytoplasmic Nissl bodies (*) and euchromatic nuclei $(\mathrm{N})$ with healthy main structural components are evident. (e) Motor neurons (white arrows), glia (black arrows), and also capillaries (black arrowheads) can be seen in normal structural organization in semithin sections of delayed repair with FK506 group. (f) The area around the perikaryon reveals separations in some places (arrows). Neuropils $(*)$, astrocytes $(A)$, mitochondria (M), Golgi apparatus (G) and euchromatic nuclei have normal appearance in the delayed repair with FK506 group. (g) Motor neurons (white arrows), glia (black arrows), myelinated axons (white arrowheads) and capillaries (black arrowheads) display structural organization in semithin sections of delayed repair with FK506 group. (h) The neuropils (*) have dense edema and deformation as displayed in transmission electron micrographs of the delayed repair without FK506 group. Abnormally enlarged cisterns of granulated endoplasmic reticulum (arrows) and also Nissl bodies (N) in dendrites (D) were spectacular observations of ultrastructure in these groups. [Color figure can be viewed in the online issue, which is available at www.anatomy.org.tr]

a predegenerated nerve, as a certain time was allowed after cut of the facial nerve. Meanwhile, Wallerian degeneration occurred on the distal part of the nerve, debris of myelin was phagocytized, and atrophic changes were evident in the target muscle. They reported that the coaptation of the freshly cut hypoglossal nerve with predegenerated facial nerve would be a more appropriate way to investigate the effect of the delayed repair. Using this model, the researchers coaptated the freshly cut hypoglossal nerve to the predegenerated facial nerve after the postoperative days $7,14,56,112$, and 224 . The delayed repair was reflected by an increase in neurons labeled with HRP, whereas decreases in cross-section area of muscle of delayed repair groups. 
Sobol et al. ${ }^{[4]]}$ studied the effects of FK506 administration after primary nerve repair and reported that nerve regeneration was significantly increased after administration within 3 days, while a 5 day delay in the nerve repair caused little or no effect. Therefore, it was concluded that FK506 was effective when given immediately after injury. In our study, delayed administration of FK506 after repair displayed a beneficial effect on the motor neuron ultrastructure, but primary repair was more effective when FK506 treatment started immediately after injury.

\section{Conclusion}

FK506 is used to provide functional recovery at early period of peripheral nerve injury. Beneficial effects of FK506 were determined in both groups of primary and delayed repair. Application of the FK506 treatment after primary repair gave better ultrastructural and functional results. Our literature search revealed no article, describing beneficial effects of FK506 administration on sciatic motor neurons after primary and delayed repair.

\section{Acknowledgements}

This study was supported by Akdeniz University Research Fund (2007.01.0103.004).

\section{References}

1. Aldskogius H, Kozlova EN. Central neuron-glial and glial-glial interactions following axon injury. Prog Neurobiol 1998;55:1-26.

2. Bisby MA, Tetzlaff $W$. Changes in cytoskeletal protein synthesis following axon injury and during axon regeneration. Mol Neurobiol 1992;6:107-23.

3. de la Cruz RR, Pastor AM, Delgado-Garcia JM. Influence of the postsynaptic target on the functional properties of neurons in the adult mammalian central nervous system. Rev Neurosci 1996;7:11549.

4. Lowrie MB, Vrbova G. Dependence of postnatal motoneurones on their targets: review and hypothesis. Trends Neurosci 1992;15:80-4.

5. Hefti F. Pharmacology of neurotrophic factors. Annu Rev Pharmacol Toxicol 1997;37:239-67.

6. Lindsay RM. Neurotrophins and receptors. Prog Brain Res 1994;103:3-14.

7. Muller HW. Gene expression in nerve regeneration. Diabet Med 1996;13:682.

8. Sendtner M. Neurotrophic factors for experimental treatment of motoneuron disease. Prog Brain Res 1996;109:365-71.

9. Terenghi G. Peripheral nerve regeneration and neurotrophic factors. J Anat 1999;194:1-14.

10. Snider WD, Elliott JL, Yan Q. Axotomy-induced neuronal death during development. J Neurobiol 1992;23:1231-46.

11. Hoffmann CF, Choufoer H, Marani E, Thomeer RT. Ultrastructural study on avulsion effects of the cat cervical motoaxonal pathways in the spinal cord. Clin Neurol Neurosurg 1993;95: S39-47.
12. Martin LJ, Kaiser A, Price AC. Motor neuron degeneration after sciatic nerve avulsion in adult rat evolves with oxidative stress and is apoptosis. J Neurobiol 1999;40:185-201.

13. Novikov L, Novikova L, Kellerth JO. Brain-derived neurotrophic factor promotes survival and blocks nitric oxide synthase expression in adult rat spinal motoneurons after ventral root avulsion. Neurosci Lett 1995;200:45-8.

14. $\mathrm{Wu}$ W. Expression of nitric-oxide synthase (NOS) in injured CNS neurons as shown by NADPH diaphorase histochemistry. Exp Neurol 1993;120:153-9.

15. Tandrup T, Woolf CJ, Coggeshall RE. Delayed loss of small dorsal root ganglion cells after transection of the rat sciatic nerve. J Comp Neurol 2000;422:172-80.

16. Johnson IP, Duberley RM. Motoneuron survival and expression of neuropeptides and neurotrophic factor receptors following axotomy in adult and ageing rats. Neuroscience 1998;84:141-50.

17. Mattsson P, Meijer B, Svensson M. Extensive neuronal cell death following intracranial transection of the facial nerve in the adult rat. Brain Res Bull 1999;49:333-41.

18. Tornqvist E, Aldskogius H. Motoneuron survival is not affected by the proximo-distal level of axotomy but by the possibility of regenerating axons to gain access to the distal nerve stump. J Neurosci Res 1994;39:159-65.

19. Yu WH. Regulation of nitric oxide synthase expression in motoneurons following nerve injury. Dev Neurosci 1997;19:247-54.

20. Arvidsson J, Aldskogius H. Effect of repeated hypoglossal nerve lesions on the number of neurons in the hypoglossal nucleus of adult rats. Exp Neurol 1982;75:520-4.

21. Crews LL, Wigston DJ. The dependence of motoneurons on their target muscle during postnatal development of the mouse. J Neurosci 1990;10:1643-53.

22. Johnson IP, Sears TA, Hunter AS. Retrograde response to axotomy of motoneurons in the thoracic spinal cord of the aging cat. Neurobiol Aging 1991;12:151-60.

23. Kuzis K, Coffin JD, Eckenstein FP. Time course and age dependence of motor neuron death following facial nerve crush injury: role of fibroblast growth factor. Exp Neurol 1999;157:77-87.

24. Anneser JM, Berthele A, Borasio GD, Castro-Lopes JM, Zieglgansberger W, Tolle TR. Axotomy of the sciatic nerve differentially affects expression of metabotropic glutamate receptor mRNA in adult rat motoneurons. Brain Res 2000;868:215-21.

25. Vanden Noven S, Wallace N, Muccio D, Turtz A, Pinter MJ. Adult spinal motoneurons remain viable despite prolonged absence of functional synaptic contact with muscle. Exp Neurol 1993;123:14756.

26. Kim HS, Park YI. Isolation and identification of a novel microorganism producing the immunosuppressant tacrolimus. J Biosci Bioeng 2008;105:418-21.

27. Abraham RT, Wiederrecht GJ. Immunopharmacology of rapamycin. Annu Rev Immunol 1996;14:483-510.

28. Dumont FJ, Ok H, Lin S, Kastner CA, Cryan J, Martin MM, Wiederrecht G, Staruch MJ. Mixed agonist/antagonist activity of an FK-506-related immunosuppressant: biological and biochemical characterization. J Pharmacol Exp Ther 1996;276:1078-88.

29. Brenner MJ, Fox IK, Kawamura DH, Yu VM, Lowe JB 3rd, Hunter DA, Mackinnon SE. Delayed nerve repair is associated with diminished neuroenhancement by FK506. Laryngoscope 2004;114:570-6.

30. Costantini LC, Chaturvedi P, Armistead DM, McCaffrey PG, Deacon TW, Isacson O. A novel immunophilin ligand: distinct branching effects on dopaminergic neurons in culture and neu- 
rotrophic actions after oral administration in an animal model of Parkinson's disease. Neurobiol Dis 1998;5:97-106.

31. Arii T, Kamiya T, Arii K, Ueda M, Nito C, Katsura KI, Katayama Y. Neuroprotective effect of immunosuppressant FK506 in transient focal ischemia in rat: therapeutic time window for FK506 in transient focal ischemia. Neurol Res 2001;23:755-60.

32. Ebisu T, Katsuta K, Fujikawa A, Aoki I, Umeda M, Naruse S, Tanaka C. Early and delayed neuroprotective effects of FK506 on experimental focal ischemia quantitatively assessed by diffusionweighted MRI. Magn Reson Imaging 2001;19:153-60.

33. Sharkey J, Butcher SP. Immunophilins mediate the neuroprotective effects of FK506 in focal cerebral ischaemia. Nature 1994;371:336-9.

34. Bavetta S, Hamlyn PJ, Burnstock G, Lieberman AR, Anderson PN. The effects of FK506 on dorsal column axons following spinal cord injury in adult rats: neuroprotection and local regeneration. Exp Neurol 1999;158:382-93.

35. Madsen JR, MacDonald P, Irwin N, Goldberg DE, Yao GL, Meiri KF, Rimm IJ, Stieg PE, Benowitz LI. Tacrolimus (FK506) increases neuronal expression of GAP-43 and improves functional recovery after spinal cord injury in rats. Exp Neurol 1998;154:673-83.

36. Gold BG, Yew JY, Zeleny-Pooley M. The immunosuppressant FK506 increases GAP-43 mRNA levels in axotomized sensory neurons. Neurosci Lett 1998;241:25-8.

37. Lyons WE, George EB, Dawson TM, Steiner JP, Snyder SH. Immunosuppressant FK506 promotes neurite outgrowth in cultures of PC12 cells and sensory ganglia. Proc Natl Acad Sci USA 1994;91:3191-5.

38. Gold BG, Gordon HS, Wang MS. Efficacy of delayed or discontinuous FK506 administrations on nerve regeneration in the rat sciatic nerve crush model: lack of evidence for a conditioning lesion-like effect. Neurosci Lett 1999;267:33-6.

39. Gold BG, Katoh K, Storm-Dickerson T. The immunosuppressant FK506 increases the rate of axonal regeneration in rat sciatic nerve. J Neurosci 1995;15:7509-16.

40. Lee M, Doolabh VB, Mackinnon SE, Jost S. FK506 promotes functional recovery in crushed rat sciatic nerve. Muscle Nerve 2000;23:633-40.

41. Wang MS, Zeleny-Pooley M, Gold BG. Comparative dose-dependence study of FK506 and cyclosporin A on the rate of axonal regeneration in the rat sciatic nerve. J Pharmacol Exp Ther 1997;282: 1084-93.

42. Navarro X, Udina E, Ceballos D, Gold BG. Effects of FK506 on nerve regeneration and reinnervation after graft or tube repair of long nerve gaps. Muscle Nerve 2001;24:905-15.

43. Sarikcioglu L, Duygulu E, Aydin H, Gurer EI, Ozkan O, Tuzuner S. Effects of intrathecal administration of FK506 after sciatic nerve crush injury. J Reconstr Microsurg 2006;22:649-54.

44. Sobol JB, Lowe IJ, Yang RK, Sen SK, Hunter DA, Mackinnon SE. Effects of delaying FK506 administration on neuroregeneration in a rodent model. J Reconstr Microsurg 2003;19:113-8.

45. Chunasuwankul R, Ayrout C, Dereli Z, Gal A, Lanzetta M, Owen E. Low dose discontinued FK506 treatment enhances peripheral nerve regeneration. Int Surg 2002;87:274-8.

46. Jost SC, Doolabh VB, Mackinnon SE, Lee M, Hunter D. Acceleration of peripheral nerve regeneration following FK506 administration. Restor Neurol Neurosci 2000;17:39-44.

47. Sulaiman OA, Midha R, Munro CA, Matsuyama T, Al-Majed A, Gordon T. Chronic Schwann cell denervation and the presence of a sensory nerve reduce motor axonal regeneration. Exp Neurol 2002;176:342-54
48. Sulaiman OA, Voda J, Gold BG, Gordon T. FK506 increases peripheral nerve regeneration after chronic axotomy but not after chronic schwann cell denervation. Exp Neurol 2002;175:127-37.

49. Pockett S, Gavin RM. Acceleration of peripheral nerve regeneration after crush injury in rat. Neurosci Lett 1985;59:221-4.

50. Doolabh VB, Mackinnon SE. FK506 accelerates functional recovery following nerve grafting in a rat model. Plast Reconstr Surg 1999; 103:1928-36.

51. Fansa H, Keilhoff G, Altmann S, Plogmeier K, Wolf G, Schneider $W$. The effect of the immunosuppressant FK 506 on peripheral nerve regeneration following nerve grafting. J Hand Surg Br 1999; 24:38-42.

52. Yang RK, Lowe JB, 3rd, Sobol JB, Sen SK, Hunter DA, Mackinnon SE. Dose-dependent effects of FK506 on neuroregeneration in a rat model. Plast Reconstr Surg 2003;112:1832-40.

53. Buttemeyer R, Rao U, Jones NF. Peripheral nerve allograft transplantation with FK506: functional, histological, and immunological results before and after discontinuation of immunosuppression. Ann Plast Surg 1995;35:396-401.

54. Grand AG, Myckatyn TM, Mackinnon SE, Hunter DA. Axonal regeneration after cold preservation of nerve allografts and immunosuppression with tacrolimus in mice. J Neurosurg 2002;96:924-32.

55. Weinzweig N, Grindel S, Gonzalez M, Kuy D, Fang J, Shahani B. Peripheral-nerve allotransplantation in rats immunosuppressed with transient or long-term FK-506. J Reconstr Microsurg 1996;12:451-9.

56. Bignotti B, Origo C, Schenone A, Ratto S, Mancardi GL, Ferrari ML. Experimental studies on peripheral nerve repair following early or delayed suture. Ital J Orthop Traumatol 1986;12:259-66.

57. Bolesta MJ, Garrett WE Jr, Ribbeck BM, Glisson RR, Seaber AV, Goldner JL. Immediate and delayed neurorrhaphy in a rabbit model: a functional, histologic, and biochemical comparison. J Hand Surg Am 1988;13:352-7.

58. Fu SY, Gordon T. Contributing factors to poor functional recovery after delayed nerve repair: prolonged denervation. J Neurosci 1995;15:3886-95.

59. Grabb WC. Median and ulnar nerve suture. An experimental study comparing primary and secondary repair in monkeys. J Bone Joint Surg Am 1968;50:964-72.

60. Irintchev A, Draguhn A, Wernig A. Reinnervation and recovery of mouse soleus muscle after long-term denervation. Neuroscience 1990;39:231-43.

61. Van Beek A, Glover JL, Zook E. Primary versus delayed-primary neurorrhaphy in rat sciatic nerve. J Surg Res 1975;18:335-9.

62. Wang MS, Gold BG. FK506 increases the regeneration of spinal cord axons in a predegenerated peripheral nerve autograft. J Spinal Cord Med 1999;22:287-96.

63. Kujawa KA, Jones KJ. Testosterone-induced acceleration of recovery from facial paralysis in male hamsters: temporal requirements of hormone exposure. Physiol Behav 1990;48:765-8.

64. Kujawa KA, Kinderman NB, Jones KJ. Testosterone-induced acceleration of recovery from facial paralysis following crush axotomy of the facial nerve in male hamsters. Exp Neurol 1989;105:80-5.

65. de Medinaceli L, Freed WJ, Wyatt RJ. An index of the functional condition of rat sciatic nerve based on measurements made from walking tracks. Exp Neurol 1982;77:634-43.

66. Carlton JM, Goldberg NH. Quantitating integrated muscle function following reinnervation. Surg Forum 1986;37:611-2. 
67. Bain JR, Mackinnon SE, Hunter DA. Functional evaluation of complete sciatic, peroneal, and posterior tibial nerve lesions in the rat. Plast Reconstr Surg 1989;83:129-38.

68. Fu SY, Gordon T. Contributing factors to poor functional recovery after delayed nerve repair: prolonged axotomy. J Neurosci 1995;15:3876-85.

69. Kobayashi J, Mackinnon SE, Watanabe O, Ball DJ, Gu XM, Hunter DA, Kuzon WM Jr. The effect of duration of muscle denervation on functional recovery in the rat model. Muscle Nerve 1997;20:858-66.

70. Totosy de Zepetnek JE, Zung HV, Erdebil S, Gordon T. Innervation ratio is an important determinant of force in normal and reinnervated rat tibialis anterior muscles. J Neurophysiol 1992;67: 1385-403.

71. Viguie CA, Lu DX, Huang SK, Rengen H, Carlson BM. Quantitative study of the effects of long-term denervation on the extensor digitorum longus muscle of the rat. Anat Rec 1997;248: $346-54$.

72. Gordon T, Fu SY. Long-term response to nerve injury. Adv Neurol 1997;72:185-99.

73. Sulaiman OA, Gordon T. Effects of short- and long-term Schwann cell denervation on peripheral nerve regeneration, myelination, and size. Glia 2000;32:234-46.
74. Hizay A, Demirel BM, Gokhan G, Sarikcioglu L, Demir N. Does FK506 reduce the size of the watershed area after vascular injury of the sciatic nerve? Rom J Morphol Embryol 2011;52:1077-80.

75. Sarikcioglu L, Demir N, Akar Y, Demirtop A. Effect of intrathecal FK506 administration on intraorbital optic nerve crush: an ultrastructural study. Can J Ophthalmol 2009;44:427-30.

76. Utuk A, Sarikcioglu L, Demirel BM, Demir N. The immunosuppressive agent FK506 prevents subperineurial degeneration and demyelination on ultrastructural and functional analysis. Curr Neurovasc Res 2009;6:252-8.

77. Yildirim FB, Sarikcioglu L, Ozsoy U, Demir N, Demirtop A, Ucar Y. Effect of FK506 administration after obturator nerve injury: a functional and ultrastructural study. Acta Neurobiol Exp (Wars) 2008; 68:477-83.

78. Ma J, Novikov LN, Wiberg M, Kellerth JO. Delayed loss of spinal motoneurons after peripheral nerve injury in adult rats: a quantitative morphological study. Exp Brain Res 2001;139:216-23.

79. Guntinas-Lichius O, Effenberger K, Angelov DN, Klein J, Streppel M, Stennert E, Neiss WF. Delayed rat facial nerve repair leads to accelerated and enhanced muscle reinnervation with reduced collateral axonal sprouting during a definite denervation period using a cross-anastomosis paradigm. Exp Neurol 2000;162:98-111.

Correspondence to: Fatoş Belgin Yıldırım, PhD

Department of Anatomy, Faculty of Medicine,

Akdeniz University, 07070, Antalya, Turkey

Phone: +90242 2274485

e-mail: yildirimfb@akdeniz.edu.tr

Conflict of interest statement: No conflicts declared.

This is an open access article distributed under the terms of the Creative Commons Attribution-NonCommercial-NoDerivs 3.0 Unported (CC BY-NCND3.0) Licence (http://creativecommons.org/licenses/by-nc-nd/3.0/) which permits unrestricted noncommercial use, distribution, and reproduction in any medium, provided the original work is properly cited. Please cite this article as: Özsoy U, Yıldırım FB, Demirel BM, Hızay A, Sarıkcıŏlu L, Demir N, Tanrı̈ver G, Süzen B, Oğuz N. Effect of FK506 administration in alpha motor neurons after primary and delayed repair of the sciatic nerve. Anatomy 2016;10(1):30-39. 